Outlines of Structural Geology

By Dr. E. Sherbon Hills. Pp. ix $+172+4$ plates. (London: Methuen and Co., Ltd., 1940.) 6s. $6 d$.

THE author of this admirable little book tells us that his aim has been to present "a brief, yet reasonably complete and well-documented summary of structural geology, with special reference to those aspects of the subject with which the field geologist should be acquainted". Dr. Hills has been highly successful in attaining his object. The chapters deal in turn with non-diastrophic structures (for example, primary structures of sediments, effects of moving ice and subaqueous slumping) ; mechanical principles of rock deformation ; major crustal structures ; folds (geometry and description, mechanics of formation, and associated structures such as joints and cleavage); faults (nomenclature, description, and associated structures, such as slickensides and tension fractures); structures of igneous rocks (flow, fracture and tectonic relationships); and finally, petrofabric analysis.

The last two chapters, giving for the first time in an English text-book a concise and reliable account of the results of recent work in two difficult but profitable fields of research, will be particularly welcomed. Topics such as isostasy and the fundamental causes of diastrophism have been omitted, quite properly, in a book of this scope. There are, nevertheless, instructive discussions of geosynclines, nappes and other alpine structures, and rift valleys. In connexion with the last of these, one is glad to see full reference to Wayland's compression hypothesis and the support given it by Bullard's gravity measurements across the African rifts. Indeed, the book is commendably up to date throughout, and ample guidance to wider reading is provided by numerous and well-chosen references to the leading literature.

The book is copiously illustrated with very clear and well-drawn diagrams and figures, and these, together with an effective series of excellently reproduced photographs, add greatly to its educational value. Both as an introduction to the subject and as a sound and balanced review of its present status the book can be strongly recommended to students, teachers and geologists in general, by all of whom it should be highly appreciated.

\section{Advanced Readings in Chemical and Technical German}

From Practical Reference Books; with a Summary of Reading Difficulties, a Frequency Vocabulary List and Notes. Selected and edited by Prof. John Theodore Fotos and Prof. R. Norris Shreve. Pp. xliii+304. (Now York: John Wiley and Sons, Inc.; London : Chapman and Hall, Ltd., 1940.) 15s. net. $7 \mathrm{HE}$ selections for translation given in this book 1 have been chosen from seven standard works of reference in German, which cover inorganic and organic chemistry and metallurgy. No explanation is given as to why physical chemistry has been excluded, and the omission seems curious. There is an introduction giving some points of German grammar and construction which would be useful in revision. A minimum chemical German vocabulary arranged in numbered order of frequency of occurrence follows. Since physical chemistry is not represented in the book, this order is purely accidental and of no real value.

The extracts for reading follow, each with a vocabulary and notes explaining points of interest or difficulty. These extracts are full of arithmetical numbers, but no table of German equivalents of these is given, so that anyone reading " $19,25^{\circ}$ " would be likely to think of the English rather than the German words for this.

There is no doubt that this book should prove useful, although the highly condensed style of the works of reference used as sources does not provide a representative specimen of the journal literature, which is probably consulted to an even larger degree.

\section{New Style Exercises in Biology}

Part 1: Botany. By F. Whitwam Jones. Pp. 64. (London: J. M. Dent and Sons, Ltd., 1940.) 1s. 4 d. T $\mathrm{F}$ only for its novelty, Mr. Whitwam Jones's book 1 is worthy of earnest consideration. It consists $o$ : a series of detachable pages containing a variety of exercises and questions which, according to the author, should help the pupil of School Certificate standard to confirm, apply and extend the knowledge which he has gained during his school training. As an interesting attempt to help pupils to attach thoughts to words, the book must be well praised. Yet one of the great dangers of instruction of this kind would appear to lie in the development of a rigid uniformity in the type of apparatus used in each school in order to make the student familiar with the "classic" experiments in vogue at the time. This would inevitably lead to a sidetracking of initiative in teaching method and to considerablf restriction in improvization in the devising oe experimental material, factors which are of the greatest importance in the progress of good science teaching.

The idea behind the book is laudable, but is one that would appear to bear the richest fruit only if applied by the individual teacher each year for the pupils in his or her school. A far more serious criticism is that Mr. Jones's teaching seems to be confined to biological issues in which the extreme worth of his subject in social and human relationships is completely omitted. Perhaps this omission is rectified in the second part of this book, which is yet to be published.

T. H. H.

\section{French-English Science Dictionary}

For Students in Agricultural, Biological, and Physical Sciences. By Prof. Louis DeVries, with the collaboration of Members of the Graduate Faculty. Pp. viii +546 . (New York and London: McGraw-Hill Book Co., Inc., 1940.) 24s. 6d.

7 HIS dietionary of 43,000 entries includes terms of agricultural, physical, chemical, geological, medical and biological interest as well as many literary terms. About five hundred idioms are also given. A list of French abbreviations and their translation into English is appended. The book should be useful to all students of science. 